\title{
Gait characteristics of younger-old and older-old adults walking overground and on a compliant surface
}

\section{Características da marcha de idosas jovens e muito idosas em solo estável e sobre superfície complacente}

\author{
Rita C. S. Bárbara', Sandra M. S. F. Freitas', Leia B. Bagesteiro², Mônica R. Perracini', Sandra R. Alouche'
}

\begin{abstract}
Background: Walking across unstable surfaces disturbs normal stability and efficient strategies must be used to avoid falls. This study identified age-related changes in gait during unstable surface walking. Method: Eight healthy younger-old adults (YOG, mean age, 68.6 years) and eight healthy older-old adults (OOG, mean age, 82.1 years) were assessed. Both groups performed the Timed Up and Go Test (TUG) and walked on a rigid and on a compliant surface while kinematic data were obtained. Results: The OOG needed more time to complete the TUG test compared to YOG $\left(F_{1,14}=5.18 ; p=0.04\right)$. The gait speed, stride length and vertical displacement of the foot were similar for both groups, but they were slower $\left(F_{114}=5.64 ; p=0.03\right)$ when walking on the compliant surface. The knee and hip range of motion on the sagittal plane $\left(F_{1,14}=191.9 ; p<0.001\right.$ and $F_{1,14}=36.4, p<0,001$, respectively $)$ increased on the complaint surface but no group effect was found. The displacement of upper trunk on the frontal plane was similar between groups $\left(F_{1,14}=2.43\right.$; $p=0.14)$ and conditions $\left(F_{1,14}=1.15 ; p=0.3\right)$. The $O O G$ had greater displacement of the pelvic segment on the frontal plane than the $Y O G$ $\left(F_{1,14}=4.9 ; p=0.04\right)$ mainly for the complaint surface. Conclusion: Older-old individuals have slower TUG test and greater displacement of the pelvic segment on a compliant surface. More challenging tasks and/or environment should be used for gait assessment and intervention of older adults with risk of falls.
\end{abstract}

Key words: aging; gait; biomechanics; aged; movement.

\section{Resumo}

Contextualização: Caminhar em superfícies instáveis perturba a estabilidade corporal, e estratégias eficientes devem ser utilizadas para evitar quedas. Objetivo: Identificar alterações da marcha relacionadas ao envelhecimento durante a caminhada em superfície instável. Método: Oito idosos jovens sadios (GIJ, idade média, 68,6 anos) e oito idosos muito idosos sadios (GMI, idade média, 82,1 anos) foram avaliados. Ambos os grupos realizaram o Teste Timed Up and Go (TUG) e andaram sobre uma superfície rígida e uma complacente, enquanto dados cinemáticos foram registrados. Resultados: O GMI levou mais tempo para completar o TUG quando comparado ao GlJ $\left(F_{1,14}=5,18 ; p=0,04\right)$. A velocidade, o comprimento do passo e o deslocamento vertical do pé foram similares entre os grupos, e ambos foram mais lentos $\left(F_{1,14}=5,64 ; p=0.03\right)$ ao andar sobre a superfície complacente. A amplitude de movimento do joelho e do quadril no plano sagital $\left(F_{1,14}=191,9 ; p<0,001\right.$ e $F_{1,14}=36,4, p<0,001$, respectivamente) aumentaram na superfície complacente, mas nenhuma diferença entre os grupos foi encontrada. O deslocamento do tronco superior no plano frontal foi similar entre os grupos $\left(F_{1,14}=2,43 ; p=0,14\right)$ e condições $\left(F_{1,14}=1,15 ; p=0,3\right)$. $O$ GMI teve maior deslocamento do segmento da pelve no plano frontal do que o GIJ $\left(F_{1,14}=4,9 ; p=0,04\right)$, principalmente na superfície complacente. Conclusão: Indivíduos muito idosos são mais lentos no TUG e apresentam maior deslocamento do segmento pélvico na superfície complacente. Tarefas e/ou ambientes mais desafiadores deveriam ser usados para avaliação da marcha e intervenção em idosos com risco de quedas.

Palavras-chave: envelhecimento; marcha; biomecânica; idoso; movimento.

Received: 11/17/2011 - Revised: 03/01/2012 - Accepted: 04/24/2012

\footnotetext{
Masters in Physical Therapy,Universidade Cidade de São Paulo (UNICID), São Paulo, SP, Brazil

${ }^{2}$ Universidade Federal do ABC, Santo André, SP, Brazil

Correspondence to: Sandra Regina Alouche, Programa de Mestrado em Fisioterapia, Universidade Cidade de São Paulo, Rua Cesário Galeno, 448/475, Tatuapé, CEP 03071-000, São Paulo, SP, Brasil, e-mail: salouche@uol.com.br
} 


\section{Introduction $: \because$.}

Walking across unstable surfaces is a common daily life situation. Changes in surface compliance disturb normal dynamic stability. Compliant surfaces cause an inability to use the kinesthetic information accurately and make a mechanical perturbation on gait $^{1}$. In this way, people must use efficient strategies for avoiding falls and injuries. Although the causes of falling are multiple and complex, a critical factor is the ability to maintain stability and respond to perturbations during walking ${ }^{2}$. Walking is considered a complex motor skill derived from the interaction of multiple sensorimotor and cognitive processes, which are commonly impaired in frail older adults, increasing the risk of falls and mobility disability ${ }^{3-5}$.

Studies describing how older adults manage the task of controlling balance show age-related poorer performances in more demanding tests conditions, such as standing with eyes closed or in tandem position, and increased area and speed of center of pressure, assessed through a force platform. This increase showed to be more pronounced after 60 years in a sample aged from 30 till up to 80 years $^{6}$. Differently from static balance, during walking both the base of support and the center of mass are moving. The ability for developing strategies to keep balance during walking in a challenging environment ${ }^{7,8}$ and on different surfaces with young ${ }^{1}$ and aged healthy individuals ${ }^{9,10}$ has been described in previous studies. To ensure the dynamic stability, the central nervous system tries to minimize the vertical movement of the body center of mass by changes in lower limbs movement pattern. The swing limb is placed under the falling center of mass to keep forward stability as well as a combination of lateral trunk control and lateral placement of the feet to preserve lateral stability ${ }^{4,11}$.

Physical functioning tests have showed significant agedrelated differences for older adults ${ }^{12}$. Clinical balance and mobility tests, such as the Timed Up and Go test $\left(\mathrm{TUG}^{13}\right)$, are used to evaluate balance performance, to recognize any functional decline and to predict risk of falls ${ }^{14}$. Gait speed is considered a good measure of overall walking performance because it reflects energetic efficiency, muscle strength, balance control and endurance ${ }^{6}$. Slower walking can predict hospitalization ${ }^{15}$, survival $^{16}$, and falls in older adults ${ }^{17}$. In a sample of 34,485 community-dwelling older adults aged 65 years or older from 9 cohort studies the average gait speed was $0.86 \mathrm{~m} / \mathrm{s}$ (Standard Deviation $=0.22 \mathrm{~m} / \mathrm{s}$ ). Slower gait speed is associated with increased risk of falls. Each $0.10 \mathrm{~m} / \mathrm{s}$ decrease in gait speed was associated with a $7 \%$ increased risk for falls ${ }^{18}$.

It is not clear if gait performance is more strongly affected under challenging situations, like compliant surfaces, due to the age-related deterioration upon motor control systems when compared with customary walking. It is suggested that there is an increased difficulty in implementing rapid adjustments to overcome the increased demand with aging. The maximal double step length test used to evaluate the dynamic balance in the elderly was significantly correlated to age ${ }^{19}$. When walking on compliant surfaces, older and young adults decreased velocity and increased cadence ${ }^{20}$. A recent study observed an exacerbated decline in gait speed and medio-lateral control of the hip, which is explicitly evident during challenging walking ${ }^{21}$. To effectively walking on compliant surfaces, individuals with Parkinson's disease (PD) increased their stride length, step width, walking velocity and toe clearance and reduced the cadence. They also increased the vertical and medio-lateral head and pelvis displacement. These changes were different between fallers and non-fallers PD individuals ${ }^{22}$.

The analyses of age-associated changes in gait pattern among older adults are not fully explored and may bring important insights for assessment, functional training and fall risk interventions. In the present study gait parameters in the form of spatiotemporal measurement and physical functioning tests were investigated to determine age-associated changes in gait during unstable surface walking. We hypothesized that age-related (younger old adults vs. older old adults) changes in gait performance were more pronounced for unstable surface (compliant surface) walking compared with a rigid surface (overground) walking.

\section{Method $\because \therefore$.}

\section{Participants}

Sixteen female older women aged between 65 and 90 years participated in this study. They were able to walk for at least 5 meters without any external support or assistance and none of them had any associated neurological, orthopedic, cardiovascular or psychiatric conditions, dementia or pain. They were not taking medications that could affect balance or were insulin dependent. In addition, all were sedentary (e.g. did not perform physical exercises more than twice a week for $30 \mathrm{~min}$ utes) and did not have one or more falls in the last year. The experimental procedure was conducted in accordance with the Declaration of Helsinki and all participants gave approved written consent prior to participation. All procedures were approved by the Research Ethics Committee of the Universidade Cidade de São Paulo (UNICID), São Paulo, SP, Brazil, (protocol number PP13252044). 
Participants were allocated into two groups based on their age. One group was composed by eight women aged between 65 and 75 years (younger-old group, YOG), and the other was composed by eight women with 80 years old and more (olderold group, OOG).

\section{Procedure}

All participants answered a questionnaire about their fear of falling (Falls Efficacy Scale-International, FES-I) ${ }^{23}$ and performed one trial of the TUG test after familiarization with the test. Participants, dressed in black clothing, walked barefoot, along 5-m walkway (width: $1.2 \mathrm{~m}$ and height: $0.1 \mathrm{~m}$ ) at self-selected speed and returned to the initial position on five consecutive trials on overground (rigid surface) and on soft gym mats (height: $5 \mathrm{~cm}$, density: $33 \mathrm{~kg} / \mathrm{m}^{3}$ - compliant surface) placed on the walkway.

\section{Data analysis}

Movement kinematics was recorded at $60 \mathrm{~Hz}$ with three synchronized video cameras (Panasonic PV-GS35). Passive markers were bilaterally placed on the acromion process, posterior superior iliac crest, greater trochanter, femoral epicondyle, lateral malleolus and the point between the head of the second and third metatarsal. These markers were later digitized and reconstructed using the gait analysis software (APAS - Ariel Performance Analysis System - Ariel Dynamics Inc). The data were low-pass filtered at $10 \mathrm{~Hz}$ (third order, dual pass Butterworth). For the calibration, the position of a set of 12 markers were recorded and used for the reconstruction of the real coordinates by the direct linear transformation (DLT). The average root-mean-square error of the two dimensional reconstruction was $2.5 \mathrm{~mm}$. Further data analyses were performed using custom computer algorithms written in IGOR
Pro (Wavemetrics Inc.). Two gait cycles were defined (one starting with the left and other with the right heel contact) and their corresponding data sets were reduced to 200 points. The vertical displacement of the foot was calculated using the metatarsal markers to estimate foot clearance. Gait speed was calculated from the stride length and cycle time, which were also determined from the kinematic data. Ankle, knee and hip joint range of motion during stride in the sagittal plane was calculated. The displacement of upper trunk (defined by the angle formed between the line along the right and left acromion and the horizontal axis) and the pelvic (defined by the angle formed between the line along the right and left posterior superior iliac crest and the horizontal axis) segments in the frontal plane were also computed.

\section{Statistical analysis}

Statistical analyses were performed in Statistica for Windows $^{\circledR}$ (version 5.1 StatSoft, Inc., 1998). The data homogeneity and normality were confirmed by Levene and KolmogorovSmirnov Tests, respectively. Socio-demographic data, TUG Test and FES-I scores were compared by Student-T tests. Analysis of variance (ANOVA) tests were used for the between-group comparisons (young-old and older-old adults) and conditions (rigid and compliant surfaces), with the last factor considered as repeated-measure. The level of significance was set at $\mathrm{p}<0.05$.

\section{Results $\because \because$}

Table 1 summarizes the characteristics of YOG and OOG groups and the results of temporal and spatial gait parameters. All participants were able to complete the task without falls and did not report any problem with walking on compliant surface. The OOG was significantly older than the YOG. There
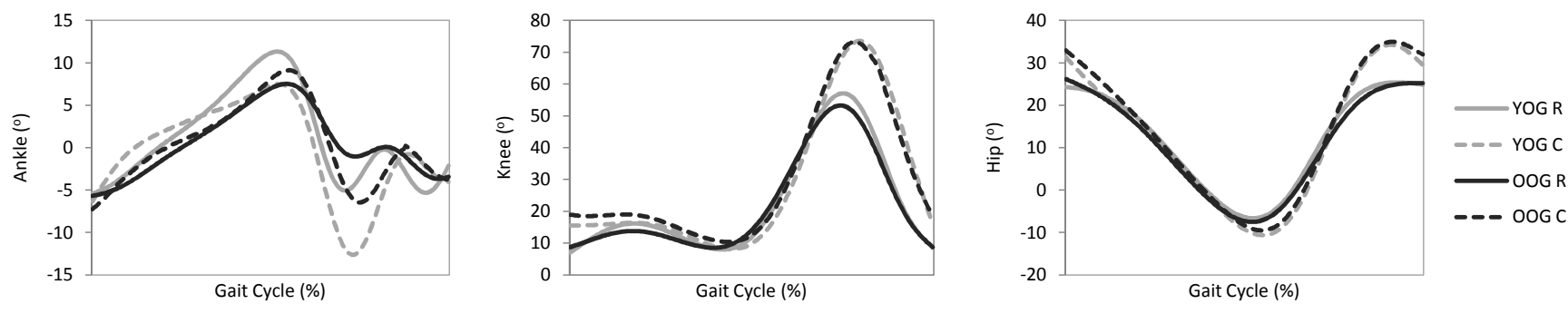

Figure 1. Average angular displacement of ankle, knee and hip joints in the sagittal plane for both groups (YOG and O0G) walking on the rigid (R) and compliant (C) surfaces. 
Table 1. Mean (SD) of the characteristics of YOG and O0G groups and Mean (SE) results of temporal, spatial and kinematic gait parameters.

\begin{tabular}{|c|c|c|c|c|}
\hline Group & \multicolumn{2}{|c|}{ YOG } & \multicolumn{2}{|c|}{ OOG } \\
\hline $\mathrm{n}$ & \multicolumn{2}{|c|}{8} & \multicolumn{2}{|c|}{8} \\
\hline Age (years) ${ }^{*}$ & \multicolumn{2}{|c|}{$68.6(2.3)$} & \multicolumn{2}{|c|}{$82.1(1.4)$} \\
\hline Height (cm) & \multicolumn{2}{|c|}{$154(5)$} & \multicolumn{2}{|c|}{$149(5)$} \\
\hline Body Mass (kg) & \multicolumn{2}{|c|}{$71.8(9)$} & \multicolumn{2}{|c|}{$62.7(10)$} \\
\hline FES-I scores & \multicolumn{2}{|c|}{$26.5(5.5)$} & \multicolumn{2}{|c|}{$27.3(6.4)$} \\
\hline \multirow[t]{2}{*}{ TUG test (seconds)* } & \multicolumn{2}{|c|}{$9.8(1.1)$} & \multicolumn{2}{|c|}{$11.8(2.2)$} \\
\hline & $\begin{array}{l}\text { Rigid } \\
\text { Surface }\end{array}$ & Compliant Surface & $\begin{array}{l}\text { Rigid } \\
\text { Surface }\end{array}$ & Compliant Surface \\
\hline Gait speed $(\mathrm{m} / \mathrm{s})^{*}$ & $0.86(0.05)$ & $0.73(0.02)$ & $0.75(0.06)$ & $0.72(0.07)$ \\
\hline Stride length (m) & $1.0(0.05)$ & $1.0(0.03)$ & $0.9(0.05)$ & $1.0(0.07)$ \\
\hline Foot vertical displacement (cm) & $11(1.3)$ & $10.7(1)$ & $10.5(0.8)$ & $12.6(0.8)$ \\
\hline Ankle ROM $\left(^{\circ}\right)$ & $24.5(1.4)$ & $28.5(2.4)$ & $23.6(2.2)$ & $27.8(2.8)$ \\
\hline Knee ROM $\left({ }^{\circ}\right)^{*}$ & $54.1(2.5)$ & $68.9(2.5)$ & $49.3(2.5)$ & $65.9(1.8)$ \\
\hline Hip ROM ()$\left.^{*}\right)^{*}$ & $37.9(2.5)$ & $47.2(1.7)$ & $36.2(1.7)$ & $47.1(2.7)$ \\
\hline Upper trunk displacement $\left({ }^{\circ}\right)$ & $2.7(0.4)$ & $2.9(0.7)$ & $3.3(0.7)$ & $4.5(0.8)$ \\
\hline Pelvic segment displacement $\left({ }^{(}\right)^{\star}$ & $5.7(0.4)$ & $4.7(0.6)$ & $6.3(0.9)$ & $7.5(0.7)$ \\
\hline
\end{tabular}

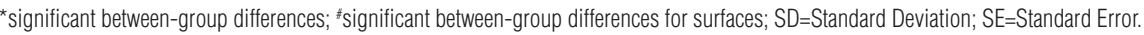

were no differences for height, body mass and FES-I scores between groups. Overall, the OOG needed more time to complete the TUG test than the YOG $(\mathrm{p}=0.04)$.

All results of temporal and spatial gait parameters had normal distribution. The ANOVA performed on gait speed revealed no differences for groups $\left(\mathrm{F}_{1,14}=0.71 ; \mathrm{p}=0.41\right)$ but a significant difference for conditions $\left(\mathrm{F}_{1,14}=5.64 ; \mathrm{p}=0.03\right)$. In addition, there was no significant interaction between these two factors $\left(\mathrm{F}_{1,14}=2.08 ; \mathrm{p}=0.17\right)$. For the stride length and vertical displacement of the foot, there was no effect of group $\left(\mathrm{F}_{1,14}=0.91\right.$; $\mathrm{p}=0.36$ and $\mathrm{F}_{1,14}=0.48 ; \mathrm{p}=0.5$, respectively $)$, conditions $\left(\mathrm{F}_{1,14}=0.88\right.$; $\mathrm{p}=0.36$ and $\mathrm{F}_{1,14}=1 ; \mathrm{p}=0.33$, respectively) or significant group vs. condition interaction $\left(\mathrm{F}_{1,14}=2.6 ; \mathrm{p}=0.13\right.$ and $\mathrm{F}_{1,14}=1.76 ; \mathrm{p}=0.21$, respectively).

Overall, individuals from YOG and OOG showed similar joint displacement profile (Figure 1). They increased the range of motion in the sagittal plane for the knee and hip joints when walking on compliant surface compared to rigid surface. This increased displacement was mostly due to greater joint flexion at the swing phase. For the knee, it was also possible to notice an increased flexion joint motion in the complaint surface since the beginning of the cycle and a small delay of the second peak of flexion. For the hip joint, the cycle realized in the complaint surface also started with an increased flexion joint motion and there was a delay in the peak of hip extension.

In fact, ANOVA revealed a main condition effect for both knee and hip range of motion $\left(\mathrm{F}_{1,14}=191.9 ; \mathrm{p}<0.001\right.$ and $\mathrm{F}_{1,14}=36.4$, $\mathrm{p}<0.001$, respectively) while the group effect were not observed for knee $\left(\mathrm{F}_{1,14}=1.6 ; \mathrm{p}=0.23\right)$ or hip $\left(\mathrm{F}_{1,14}=0.16 ; \mathrm{p}=0.7\right)$ ranges of motion. No significant effects were revealed by ANOVA to the range of motion of ankle joint.

In the frontal plane, the upper trunk and the pelvic segments displacements were analyzed (Table 1). The displacements of upper trunk were similar between groups $\left(\mathrm{F}_{1,14}=2.43\right.$; $\left.\mathrm{p}=0.14\right)$ and conditions $\left(\mathrm{F}_{1,14}=1.15 ; \mathrm{p}=0.3\right)$ as revealed by ANOVA. There were also no significant group vs. conditions interaction $\left(F_{1,14}=0.58 ; p=0.46\right)$. For the displacements of the pelvic, ANOVA indicated significant differences between groups $\left(\mathrm{F}_{1,14}=4.9\right.$; $\mathrm{p}=0.04$ ). The OOG had greater displacement of the pelvic segment than the individuals from YOG. Although there were no differences between rigid and complaint surfaces, ANOVA revealed a marginal group vs. conditions interaction $\left(\mathrm{F}_{1,14}=3.9\right.$; $\mathrm{p}=0.06$ ). Specific planned comparisons showed no differences between groups ( $\mathrm{p}=0.57)$ for the rigid surface but a significant difference $(\mathrm{p}=0.007)$ for the complaint surface.

\section{Discussion $\because \therefore$.}

This study analyzed the gait pattern of sixteen older adults when walking on a rigid and on a complaint surface. Overall, no significant differences were observed on temporal and spatial gait parameters as well as on the ranges of motion of ankle, knee and hip joints between groups. In addition, the results of upper trunk and pelvic displacement suggested a group difference only for the pelvic movement. Interestingly, this difference seemed to be more accentuated when participants walked on a challenging environment (i.e., complaint surface) than on the rigid surface. Therefore, these results suggested that the poorer performance in the TUG test observed in the old-older group when compared to younger-old group could be explained by difficulties regarding standing up and turning rather than just walking.

Walking in a compliant surface affects gait speed and requires a different joint coordination pattern. Challenging 
environment was able to differentiate between fallers and nonfallers older groups with peripheral neuropathy ${ }^{24,25}$. In general, the gait on a compliant surface requires a more dynamic movement of the trunk and the lower limbs ${ }^{1}$. The observed increased flexion of the knee and hip joints is probably to prevent tripping by maintaining toe clearance and to ensure safe forward progression. These results were similar in young adults walking over surfaces of different compliances ${ }^{9}$. As the surface compliance increases, the knee and hip flexion become higher after the toe-off and the toe elevation is maintained. Probably it represents a compensatory mechanism for keeping balance control during the challenging environment.

Age-related differences were found in frontal plane kinematics. These differences were already described for balance corrections and may be more representative of situations which induce falls in older population ${ }^{26}$. Inability to adequately control the body motion in the frontal plane can result in the lost of balance resulting in a sideways falls which is the most important risk factors for hip fractures among frail elderly ${ }^{27}$. Support-surface motion perturbations are more destabilizing in the frontal plane and the onset latencies in gluteus medius muscles delayed with age ${ }^{28}$. The higher displacement of the pelvic segment for the older-old group probably indicates less stability of the lower trunk with age. Frontal plane corrections maybe require a more complex coordination of muscle responses between the left and the right side and a greater demand on the processing requirements of the nervous system. It was observed a decline in gait speed and in mediallateral hip-generative mechanical work expenditure with age and the rate of decline was steeper for walking at fast speed revealed a lower trunk control during challenging dynamic balance tasks ${ }^{21}$. The ability to restrain lower trunk movements following disturbances imposed by environment may be a key determinant to the ability to avoid a fall ${ }^{26}$. In spite of the relatively small sample size, which is a limitation of this study, it is noteworthy that it was found a marginal interaction effect of the compliant surface on the OOG. Other studies using a larger sample should investigate this point.

The result of TUG test used to assess the dynamic balance of the participants was significant different between groups. In fact, a descriptive meta-analysis described that the average time spent to perform the test increases with age ${ }^{29}$. Our results showed similar trend of increased time with aging. Although significant differences in the TUG test performance were found between the analyzed groups, the gait speed and the mean stride length were similar between groups. No differences between ages were found in studies comparing gait parameters of young and elderly groups on irregular surfaces with normal vision condition ${ }^{30}$ like the present study.

Taken all these data together, it is possible to suggest that for categorizing age-related differences in healthy non-fallers older adults in relation to gait it may be necessary to use challenging tasks and/or environment. The prevalence of environmental risks in this population is high ${ }^{31}$ and may influence their behavior. Older adults adopts a more cautious method of negotiating obstacles ${ }^{32}$. The differences between the youngerand older-old groups became more evident in the TUG test and when walking over complaint surface. The TUG test is a mobility test, which encompasses walking, transfer and changing direction as fast as possible and the complaint surface increases the balance demand for walking. This aspect should be considered for assessment and intervention in this population. The complaint surface may offer a functionally relevant task and a tool to impose a challenge for older groups.

\section{References $: \because$.}

1. MacLellan MJ, Patla AE. Adaptations of walking pattern on a compliant surface to regulate dynamic stability. Exp Brain Res. 2006;173(3):521-30.

2. Maki BE, Mcllroy WE. Control of rapid limb movements for balance recovery: age-related changes and implications for fall prevention. Age Ageing. 2006;35 Suppl 2:ii12-8.

3. Maciel ACC, Guerra R0. Fatores associados à alteração da mobillidade em idosos residentes na comunidade. Rev Bras Fisioter. 2005;9(1):17-23.

4. Horak FB. Postural orientation and equilibrium: what do we need to know about neural control of balance to prevent falls? Age Ageing. 2006;35 Suppl 2:ii7-11

5. Wolfson L. Gait and balance dysfunction: a model of the interaction of age and disease. Neuroscientist. 2001;7(2):178-83.

6. Era P, Sainio P, Koskinen S, Haavisto P, Vaara M, Aromaa A. Postural balance in a random sample of 7,979 subjects aged 30 years and over. Gerontology. 2006;52(4):204-13.

7. Woollacott MH, Tang PF. Balance control during walking in the older adult: research and its implications. Phys Ther. 1997;77(6):646-60.
8. Shkuratova N, Morris ME, Huxham F. Effects of age on balance control during walking. Arch Phys Med Rehabil. 2004;85(4):582-8

9. Marigold DS, Patla AE. Adapting locomotion to different surface compliances: neuromuscular responses and changes in movement dynamics. J Neurophysiol. 2005;94(3):1733-50.

10. Lord SR, Menz HB. Visual contributions to postural stability in older adults. Gerontology. 2000;46(6):306-10.

11. Prince F, Corriveau H, Hébert R, Winter DA. Gait in the elderly. Gait Posture. 1997;5(2):128-35.

12. Isles RC, Choy NL, Steer M, Nitz JC. Normal values of balance tests in women aged 20-80. J Am Geriatr Soc. 2004;52(8):1367-72.

13. Podsiadlo D, Richardson S. The timed "Up \& Go": a test of basic functional mobility for frail elderly persons. J Am Geriatr Soc. 1991;39(2):142-8.

14. Corsinovi L, Bo M, Ricauda Aimonino N, Marinello R, Gariglio F, Marchetto C, et al. Predictors of falls and hospitalization outcomes in elderly patients admitted to an acute geriatric unit. Arch Gerontol Geriatr. 2009;49(1):142-5. 
15. Studenski S, Perera S, Wallace D, Chandler JM, Duncan PW, Rooney E, et al. Physical performance measures in the clinical setting. J Am Geriatr Soc. 2003;51(3):314-22.

16. Studenski S, Perera S, Patel K, Rosano C, Faulkner K, Inzitari M, et al. Gait speed and survival in older adults. JAMA. 2011;305(1):50-8.

17. Deshpande N, Metter EJ, Bandinelli S, Guralnik J, Ferrucci L. Gait speed under varied challenges and cognitive decline in older persons: a prospective study. Age Ageing. 2009;38(5):509-14

18. Verghese J, Holtzer R, Lipton RB, Wang C. Quantitative gait markers and incident fall risk in older adults. J Gerontol A Biol Sci Med Sci. 2009;64(8):896-901.

19. Demura S, Yamada T. The maximal double step length test can evaluate more adequately the decrease of physical function with age, than the maximal single step length test. Arch Gerontol Geriatr. 2011;55(1):21-4

20. Rogers HL, Cromwell RL, Grady JL. Adaptive changes in gait of older and younger adults as responses to challenges to dynamic balance. J Aging Phys Act. 2008;16(1):85-96.

21. Ko SU, Hausdorff JM, Ferrucci L. Age-associated differences in the gait pattern changes of older adults during fast-speed and fatigue conditions: results from the Baltimore longitudinal study of ageing. Age Ageing. 2010;39(6):688-94

22. Cole MH, Silburn PA, Wood JM, Worringham CJ, Kerr GK. Falls in Parkinson's disease: kinematic evidence for impaired head and trunk control. Mov Disord. 2010;25(14):2369-78.

23. Yardley L, Beyer N, Hauer K, Kempen G, Piot-Ziegler C, Todd C. Development and initial validation of the Falls Efficacy Scale-International (FES-I). Age Ageing. 2005;34(6):614-9.
24. Richardson JK, Thies SB, DeMott TK, Ashton-Miller JA. Gait analysis in a challenging environment differentiates between fallers and nonfallers among older patients with periphera neuropathy. Arch Phys Med Rehabil. 2005;86(8):1539-44.

25. Menz HB, Lord SR, St George R, Fitzpatrick RC. Walking stability and sensorimotor function in older people with diabetic peripheral neuropathy. Arch Phys Med Rehabil. 2004;85(2):245-52.

26. Grabiner MD, Donovan S, Bareither ML, Marone JR, Hamstra-Wright K, Gatts S, et al. Trunk kinematics and fall risk of older adults: translating biomechanical results to the clinic. J Electromyogr Kinesiol. 2008;18(2):197-204.

27. Hahn ME, Chou LS. Can motion of individual body segments identify dynamic instability in the elderly? Clin Biomech (Bristol, Avon). 2003;18(8):737-44.

28. Allum JH, Carpenter MG, Honegger F, Adkin AL, Bloem BR. Age-dependent variations in the directional sensitivity of balance corrections and compensatory arm movements in man. $J$ Physiol. 2002;542(Pt 2):643-63.

29. Bohannon RW. Reference values for the timed up and go test: a descriptive meta-analysis. J Geriatr Phys Ther. 2006;29(2):64-8.

30. Thies SB, Richardson JK, Ashton-Miller JA. Effects of surface irregularity and lighting on step variability during gait: a study in healthy young and older women. Gait Posture. 2005;22(1):26-31.

31. Ferrer MLP, Perracini MR, Ramos LR. Prevalência de fatores ambientais associados a quedas em idosos residentes na comunidade em São Paulo, SP. Rev Bras Fisioter. 2004:8(2):149-54.

32. Sturnieks DL, St George R, Lord SR. Balance disorders in the elderly. Neurophysiol Clin 2008:38(6):467-78. 